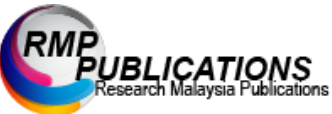

Journal of Engineering and Science Research 4 (4): 06-11, 2020

e-ISSN: 2289-7127

(C) RMP Publications, 2020

DOI: $10.26666 / \mathrm{rmp}$.jesr.2020.4.2

\title{
Design and Develop Low-Cost Device on Monitoring Environmental Indoor Air Quality in Factory
}

\author{
Mohd Azrin Mohd Said ${ }^{1,2 *}$, Shawn Felix Stephen ${ }^{1}$, Nor Kamaliana Khamis ${ }^{2}$, Abdullah Yassin ${ }^{1}$, Ana Sakura \\ Zainal Abidin ${ }^{l}$, Rudiyanto Philman Jong ${ }^{l}$, Mohamad Syazwan Zafwan bin Suffian ${ }^{l}$ and Aishah Arsad ${ }^{3}$ \\ ${ }^{1}$ Department of Mechanical and Manufacturing Engineering, Faculty of Engineering, \\ Universiti Malaysia Sarawak, 94300 Kota Samarahan, Sarawak, Malaysia \\ ${ }^{2}$ Department of Mechanical and Manufacturing Engineering, Faculty of Engineering and Built \\ Environment, Universiti Kebangsaan Malaysia Sarawak, 43600 Bangi, Malaysia \\ ${ }^{3}$ Institut Tadbiran Awam Negara (INTAN) Kampus Sarawak, 94300 Kota Samarahan, \\ Sarawak, Malaysia
}

\begin{abstract}
Environmental indoor air quality is one of the major concerns in occupational safety and health issues related to workers. Nowadays, the evolving of Internet of Things (IoT), the monitoring of the surrounding environmental desired parameters is more fascinating with the use of various sensors. Real time data now can be monitored with the Wi-Fi connection where the data being transfer across the network cloud with different platform service. This research focus is on the environmental monitoring for indoor air quality in terms of carbon monoxide (CO) in selected palm oil mill factory. This project aims to benefit the workers in a way where air quality is monitored. This low-cost device air quality monitoring (LCDAQM) used an ESPduino-32 to collect and process sensed data to the ThingSpeak platform service that can be monitored through web based or apps. The level of the carbon monoxide (CO) will light up the red LED when reach more than 50ppm which was set by OSHA. Result shows that level of CO in factory is unhealthy and need future engineering control action. The validation between LCDAQM and RS CO meter show the percentage error of $14.41 \%$. Therefore, this study will help workers and factory to monitor and reduce the occupational safety and health $(\mathrm{OSH})$ related problems to indoor air quality in factory.
\end{abstract}

Keywords: Environmental, Low-Cost EMG, Monitoring, Indoor Air Quality, CO, Factory, OSH

\section{INTRODUCTION}

In this industrial revolution era, factories are growing as it is a platform for mass production of products to be used in everyday life. A factory can be very huge in size that requires a lot of workers to function all the tools or machine to initiate mass production. The products vary from processed food, electric appliances, cleaning utensils, writing utensils, clothing, car spare parts, smart phones, cleaning chemicals, tools and many more products that requires mass production. Monitoring system can help ensure the safety of people and reduce compensation among workers.

Other than that, monitoring system can be monitoring the ultraviolet level, water level, and air quality monitoring. It will then sound alarm indicating that a dangerous level has been reached. This help to alert people to avoid certain places that are affected by dangerous condition. The alarm should not be limited by making an alarm sound. It can be emergency light, alert from a phone, or informed by a security which oversees alerting other workers. Conventionally, monitoring system for air quality are usually deals with large sizes and high costs for installation and maintenance [1]. Furthermore, it is time-consuming procedures are needed offline even though the precise data collection results can be produced [2]. Thus, air quality data is hard to gathered while offline and his may led to environmental problem issues if the data is not

*Corresponding Author: Mohd Azrin Mohd Said, Department of Mechanical and Manufacturing Engineering, Faculty of Engineering, Universiti Malaysia Sarawak, 94300 Kota Samarahan, Sarawak, Malaysia, email: msmazrin@unimas.my or $\underline{\text { mohdazrin.unimas@gmail.com }}$ 
monitored in real time. With the rapid development of Internet-of-Things (IoT) technology, nowadays wireless networks such as the wireless sensor networks (WSNs) can be one of the methodologies to transmit the sensed data [3][4] and another research using ThingSpeak in IoT in factory [5]. This help monitoring system to be more realistic and action taken would be faster.

A current research shows people tend to change their behavior and activities to improve air quality towards modern level of indoor air quality [6]. Studies indicate that indoor levels of pollutants may be two to five times higher than outdoors [6,7]. There are also several studies showed that people spend their time in enclosed environments such as offices, schools, homes, and shopping malls up to $90 \%$ from their lifetime $[8,9]$. There a lot of research has been done to monitor the indoor air quality especially in offices, school, home but rarely research in indoor air quality in factory aspects. Such a study of indoor air quality has been done are Firdhous et al. [10] develop an IoT-based IAQM system limited to monitoring Oxygen $\left(\mathrm{O}_{2}\right)$ concentrations near photocopy machines. While wireless electronic nose to detect health-endangering gases in indoor environments has been developed by Hassan et al. [11]. Lastly, Chen et al. [12] described a system for monitoring carbon dioxide $\left(\mathrm{CO}_{2}\right)$ in indoor environments.

Thus, in factory indoor air quality can be major concern towards the workers. Advanced HVAC (heating, ventilation, and air conditioning) systems use carbon dioxide (CO2) sensors to trigger an alarm and to control ventilation. While for indoor air monitoring is typically confined to smoke and carbon monoxide (CO) detectors with binary detection results [2]. Therefore, this study aims to investigate the workers exposure experience with indoor air quality in factory. It is also to monitor and test the indoor air quality $(\mathrm{CO})$ using lowcost develop device to verify the level of $\mathrm{CO}$ in the factory. This research also produces a monitoring system to alert people on the indoor air quality problem before anyone inhale the harmful gas or polluted This provide preliminary information to workers and supervisor to take further action and help to reduced OSH related problems toward workers.

\section{METHODOLOGY}

In this study, Questionnaire used to do analysis of the type of discomfort experienced by workers regarding to indoor air quality in factory. Survey were conducted among the workers of the factory. The survey was designed and pre-tested before handing it to the workers. A local palm oil mill factory located in Kota Samarahan was selected for this research to test the low-cost device (LCDAQM). The reason for selecting a palm oil mill is because it consists of boiler which run by burning oil palm fiber (mesocarp) as main fuel. The palm oil mill is known to emit smoke and $\mathrm{CO}$ from the boiler. The emission is always monitored by existing monitoring from the company released to the air from the chimney.

\section{Data Collection for Questionnaire}

The questionnaires or survey forms were designed based on establish questionnaire [13] which relates to the condition or type of work done by workers it was pretested to ensure the questions were understandable. Questionnaires were given to the workers in the factory. There are 2 shift which consist of 20 workers each shift that totals up to 40 workers. As for this experimental research, 30 subjects per group is often cited as the minimum [14].

\section{Low-cost Device Development}

\section{a. Conceptual Design}

A block diagram of the low-cost smart device was created to show a diagram showing in schematic form for the parts or components arrangement of a complex system or process. It comprises of main component, which is Microcontroller, Wi-Fi, gas sensor, Block diagram shows how the components are been used and placed. It also shows the type of data flowing in the system. Figure 1 shows the conceptual design in schematic diagram.

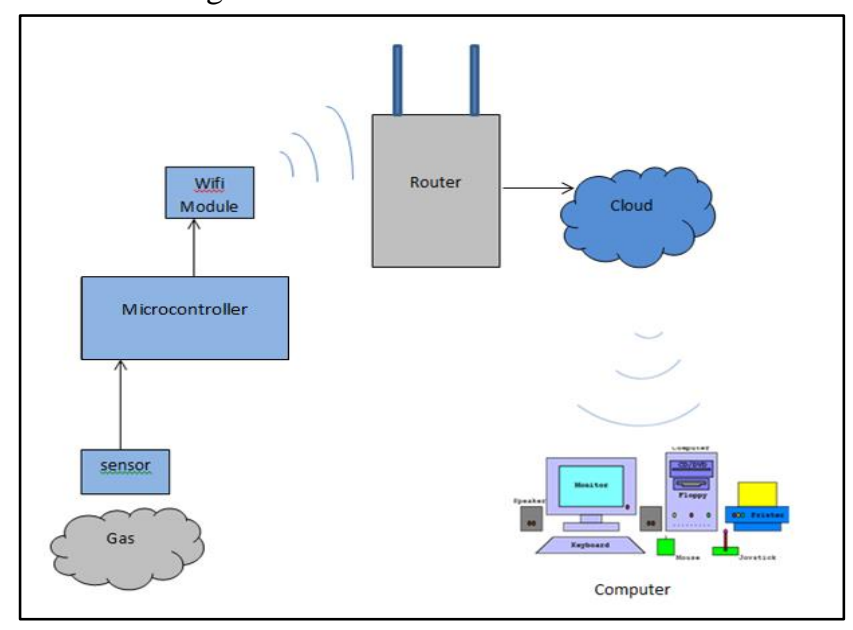

Fig 1: Schematic diagram of conceptual design

\section{b. Morphological Chart}

One of structured approach to concept generation in way of searching the best solution to a defined design problem. This can generate a complete range of alternative for low-cost device might take and it shows in Table 1. 
Table 1: Morphological chart

\begin{tabular}{|c|c|c|c|c|}
\hline Parameters & Option 1 & Option 2 & Option 3 & Option 4 \\
\hline $\begin{array}{l}\text { Material of the } \\
\text { enclosure }\end{array}$ & $\begin{array}{l}\text { Aluminium } \\
\text { Sheet }\end{array}$ & $\begin{array}{l}\text { Corrugated } \\
\text { board }\end{array}$ & $\begin{array}{l}\text { 3D Printing } \\
\text { Filament PLA } \\
\text { (Polylactic } \\
\text { Acid) }\end{array}$ & Steel Sheet \\
\hline $\begin{array}{c}\text { Manufacturing } \\
\text { method of enclosure }\end{array}$ & $\begin{array}{l}\text { Riveting the } \\
\text { sheet to form } \\
\text { an enclosure }\end{array}$ & $\begin{array}{c}\text { Material } \\
\text { removal } \\
\text { method join } \\
\text { using hot glue }\end{array}$ & 3D printing & $\begin{array}{l}\text { Welding } \\
\text { method }\end{array}$ \\
\hline Portability & Yes & Yes & Yes & Yes \\
\hline Method of Handling & Hang on wall & Sit on floor & Fixed a stand & Fixed a stand \\
\hline Sensor & MQ135 & MQ2 & MQ135 & MQ135 \\
\hline Microcontroller & Raspberry Pi 3 & Arduino Uno & ESPduino-32 & ESPduino-32 \\
\hline Power source & $9 \mathrm{~V}$ battery & USB cable & $\begin{array}{c}\text { Adapter } 12 \mathrm{~V} \\
2 \mathrm{~A}\end{array}$ & $\begin{array}{c}\text { Adapter } 12 \mathrm{~V} \\
2 \mathrm{~A}\end{array}$ \\
\hline
\end{tabular}

\section{c. Embodiment Design}

In this study the used of embodiment design in design process part starting from the principal solution or concept of a technical product. This help to develop detail design with required criteria before the production started. Configuration part of the design with selected of the predefined components are defined and all the requirement with the set of constraint need to be obey for the assembly process. Then material selection was to correspond with the desired design before getting to the final design. Table 2 shows the criteria evaluation and table 3 shows the sensors detailed selection for this lowcost LCDAQM device.

Table 2: Criteria Evaluation Table

\begin{tabular}{llll}
\hline Criteria & Arduino UNO R3 & Raspberry Pi 3 & ESPduino-32 \\
\hline Ease to use & Easy & Hard & Medium \\
Small dimension & $\begin{array}{l}68.6 \mathrm{~mm} \\
\times 53.3 \mathrm{~mm}\end{array}$ & $\begin{array}{l}85.60 \mathrm{~mm} \times 56.5 \\
\mathrm{~mm} \times 17 \mathrm{~mm}\end{array}$ & $70 \mathrm{~mm} \times 52 \mathrm{~mm}$ \\
& $\begin{array}{l}\text { Adapter 12V 2A } \\
\text { and USB type A-B }\end{array}$ & $\begin{array}{l}+5.1 \mathrm{~V} \text { micro USB } \\
\text { supply }\end{array}$ & $\begin{array}{l}\text { Adapter 12V 2A } \\
\text { and USB type A-B }\end{array}$ \\
$\begin{array}{llll}\text { Power supply } \\
\text { method }\end{array}$ & Not available & $\begin{array}{l}\text { Yes, integrated on } \\
\text { the board }\end{array}$ & $\begin{array}{l}\text { Yes, integrated on } \\
\text { the board }\end{array}$ \\
$\begin{array}{l}\text { Wi-Fi functions } \\
\text { Price estimated } \\
\text { per piece }\end{array}$ & RM 22 - RM 25 & RM 164 & RM 60 \\
\hline
\end{tabular}

Table 3: Sensors Details selection

\begin{tabular}{|c|c|c|c|c|}
\hline $\begin{array}{l}\text { Critical } \\
\text { criteria }\end{array}$ & MQ-2 & MQ-3 & MQ-9 & MQ-135 \\
\hline Ease to use & Easy & Easy & Easy & Easy \\
\hline $\begin{array}{l}\text { Small } \\
\text { dimension }\end{array}$ & $\begin{array}{c}32 \mathrm{~mm} \times 20 \\
\mathrm{~mm}\end{array}$ & $\begin{array}{c}32 \mathrm{~mm} \times 20 \\
\mathrm{~mm}\end{array}$ & $\begin{array}{c}32 \mathrm{~mm} \times 20 \\
\mathrm{~mm}\end{array}$ & $32 \mathrm{~mm} \times 20 \mathrm{~mm}$ \\
\hline $\begin{array}{l}\text { Type gas } \\
\text { detected }\end{array}$ & $\begin{array}{c}\mathrm{H} 2 \text {, LPG, CH4, } \\
\text { CO, Alcohol, } \\
\text { Smoke or } \\
\text { Propane }\end{array}$ & $\begin{array}{c}\text { Alcohol, } \\
\text { Ethanol, smoke }\end{array}$ & $\begin{array}{c}\text { Carbon } \\
\text { Monoxide, } \\
\text { flammable } \\
\text { gasses }\end{array}$ & $\begin{array}{l}\text { CO, Ammonia, } \\
\text { Benzene, } \\
\text { Alcohol, smoke }\end{array}$ \\
\hline $\begin{array}{l}\text { Price } \\
\text { estimated per } \\
\text { piece }\end{array}$ & RM 8 & RM 12 & RM 7 & RM 8 \\
\hline
\end{tabular}

\section{d. Final Design}

The final design then fabricated to produce the product of low-cost device for air quality monitoring (LCDAQM) shows in figure 2.
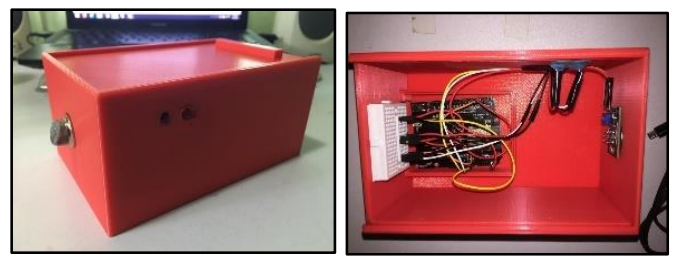

Fig 2: Final design LCDAQM

\section{e. ThingSpeak IoT Platform Service for Monitoring}

f.

To use ThingSpeak, an account must be created to make a channel to collect the data and display it to a graph. The channel must be named and define the axis names. The sharing of channel can be share public or private which can be set during the making of channel.

a. The sensor libraries need to be load in Arduino IDE Software

b. To visualize sensed data program will be executed.

c. Output can be visualized in ThingSpeak cloud by enter the Network credentials in IDE and program been executed.

\section{RESULT AND DISCUSSION}

\section{Questionnaire Result}

Based on the selected question, the questionnaires were given to the 40 respondents (workers) in the factory. Below are the findings related to indoor air quality in palm oil mill factory. Figure 3 shows the percentage of health issue experienced by workers during the past year 
of working in the palm oil mill. The most health issue symptoms have been complained by workers was sore throat $20 \%$, which might be related to the air quality of the mill. Then followed by other symptoms that relates to air quality problem.

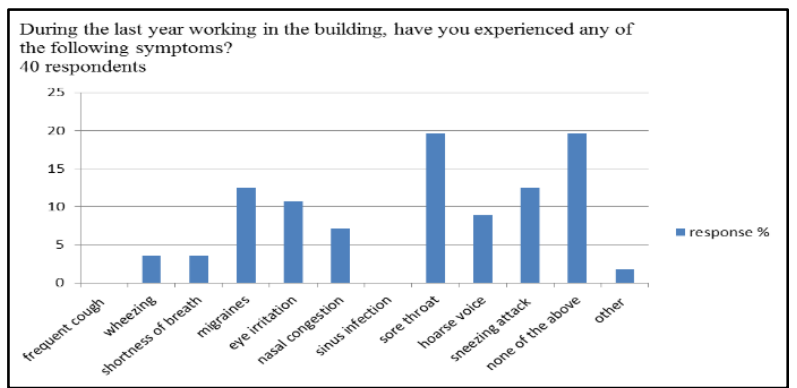

Fig 3: Health issue experienced by workers

Figure 4 show that $42.5 \%$ of workers wear their personal protective equipment (PPE) sometimes. This may be due to over confidence of a worker on their protection. Some may be lazy to wear or uncomfortable to wear the PPE which may disrupt their breath and performance. Some workers may do not have the habit of wearing PPE where it is not certain when they will wear it. This result also shows the potential cause of health problems because if the air condition happens to be bad, it will be too late to avoid as they might inhale small amount of hazardous gas before they wear PPE. However, it is crucial for the workers to wear PPE especially when working with life threatening job. Meanwhile, figure 5 shows that $90 \%$ of worker does not get any notification from the factory about the level of indoor air quality (IAQ).

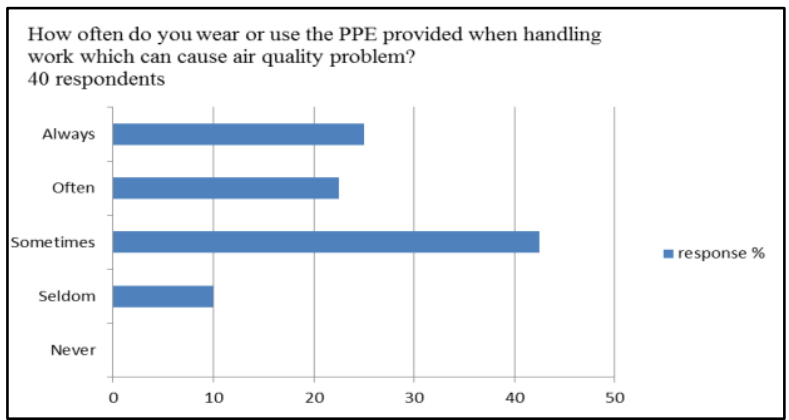

Fig 4: Percentage worker wearing PPE

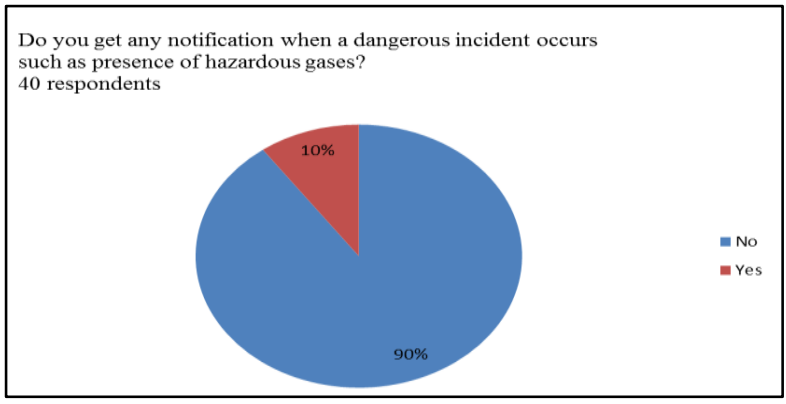

Fig 5: Percentage of awareness and notification

\section{Data Collection Analysis}

The developed low-cost device LCDAQM was tested to collect data on level of carbon monoxide present indoor of the factory then evaluated. The data collected were visualized in ThingSpeak and chart. This smart device, it is programmed to detect the level of carbon monoxide (CO). For this situation, the boiler burns the palm fruit bunches which emits smoke as by product of burning. Therefore, this device sensed this smoke that contains $\mathrm{CO}$ gas which triggers the sensor and collects the data regarding the concentration of the smoke in part per million (ppm). Figure 6 shows the data collection of CO in ppm gathered from ThingSpeak web.

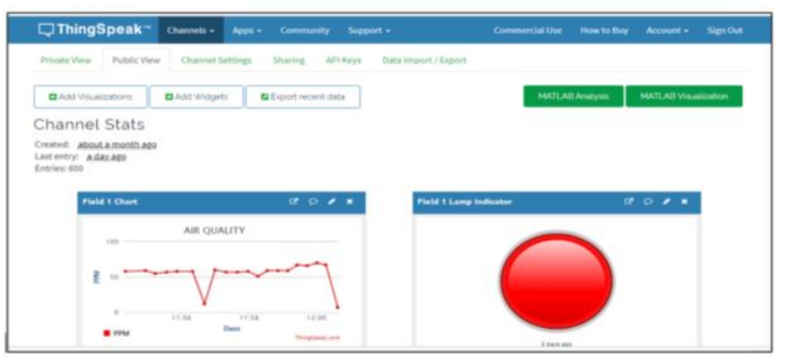

Fig 6: Data collection and monitoring

Figure 7 shows the data of air quality for 2.5 hours taken at the same area. This data shows different air quality within time. The total number of data taken for the whole 2.5 hours is 600 data. Based on the observation of the graph, it shows raise of concentration of $\mathrm{CO}$ at high level. The concentration of $\mathrm{CO}$ then drops to normal level which is below 100ppm shown by a red line in the graph. The concentration of CO rises for short period of time then drops to normal concentration. The graph show that the concentration of $\mathrm{CO}$ does not remain at very high level at most time. By referring to OSHA Carbon Monoxide (CO) Permissible Exposure Limit (PEL) for CO is 50 parts per million (ppm). OSHA standards prohibit worker to be expose to more than $50 \mathrm{ppm}$ of $\mathrm{CO}$ gas of air averaged during an 8-hour time period [15]. 


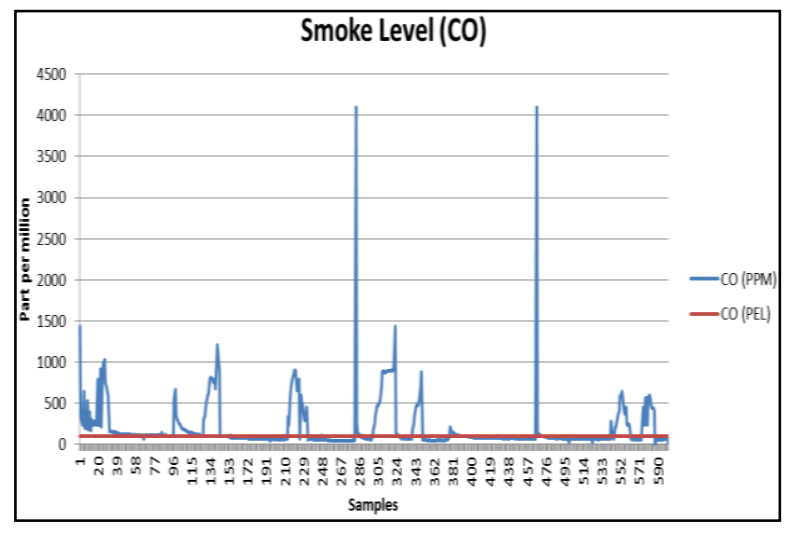

Fig 7: Indoor air quality (IAQ) in factory

\section{Validation}

For data validation, available RS Carbon Monoxide Meter has been used. The RS CO Meter data validation process was done during the data collection as shown in figure 8 . This figure 8 shows the differences between develop Low-Cost Device Air Quality Monitoring (LCDAQM) in red line color with RS Carbon Monoxide Meter (RS CO Meter) in green line color. The average percentage of error was $14.41 \%$ for this low-cost device. This show the LCDAQM can be improved to get stable data in future.

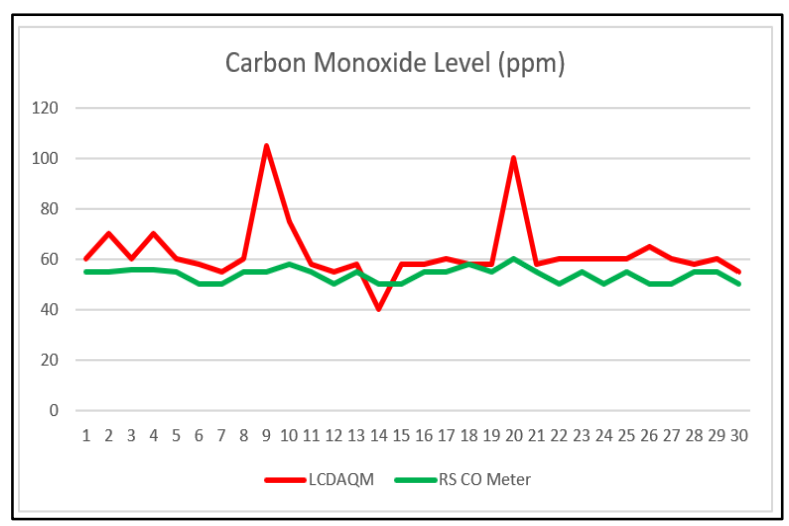

Fig 8: Comparison of $\mathrm{CO}$ level from 2 devices

\section{CONCLUSION}

This study shows that the palm oil mill factory needs to take future action in ensure the health and safety issues toward worker. As findings shows that the level of the carbon monoxide (CO) in factory are crucial when reach more than 50ppm set by OSHA guideline. To increase good environmental safety towards worker, monitoring system in factory need to be in their concern in future. This study also shows that the objectives are achieved from the investigation with the workers and the LCDAQM can be one of the solutions for the factory in reducing OSH related problem towards the worker in factory. For better result in future, comprehensive study on others sensor and tested with different would be needed to verify the initial results obtained in this study.

\section{ACKNOWLEDGMENTS}

The authors acknowledge the financial support from Osaka Gas Foundation in Cultural Exchange (OGFICE) Research Grant from Japan (IG/F02/OSAKA/02/2018), Many thanks to all the colleagues, undergraduate students from Universiti Malaysia Sarawak (UNIMAS) for assistance and involve in this research project and to Universiti Kebangsaan Malaysia (UKM) Research Grant (GUP-2019-019).

\section{REFERENCES}

[1] C K. B. Shaban, A. Kadri and E. Rezk, "Urban air pollution monitoring system with forecasting models", IEEE Sensors J., vol. 16, pp. 2598-2606, Apr. 2016.

[2] K. Zheng, S. Zhao, Z. Yang, X. Xiong and W. Xiang, "Design and Implementation of LPWABased Air Quality Monitoring System," in IEEE Access, vol. 4, pp. 3238-3245,2016, doi: 10.1109/ACCESS.2016.2582153.

[3] C. Peng, K. Qian and C. Wang, "Design and application of a VOC-monitoring system based on a ZigBee wireless sensor network", IEEE Sensors J., vol. 15, no. 4, pp. 2255-2268, Apr. 2015.

[4] S. He, J. Chen, X. Li, X. S. Shen and Y. Sun, "Mobility and intruder prior information improving the barrier coverage of sparse sensor networks", IEEE Trans. Mobile Computing., vol. 13, no. 6, pp. 1268-1282, Jun. 2014.

[5] Mohd Azrin Mohd Said, Ahmad Faridzul Japar, Nor Kamaliana Khamis, Abdullah Yassin, Ana Sakura Zainal Abidin, Rudiyanto Philman Jong, Mohamad Syazwan Zafwan bin Suffian, Aishah Arsad. Design and Develop Low-Cost Device for Monitoring Occupational Noise Exposure Toward Workers in Factory. Sci. Int. (Lahore), 32(6),729733,2020

[6] C. Peng, K. Qian and C. Wang, "Design and application of a VOC-monitoring system based on a ZigBee wireless sensor network", IEEE Sensors J., vol. 15, no. 4, pp. 2255-2268, Apr. 2015.

[7] US Environmental Protection Agency (USEPA). Indoor air quality tools for schools' Communications guide. Available at http://www.epa.gov.

[8] Klepeis, N.E.; Nelson, W.C.; Ott, W.R.; Robinson, J.P.; Tsang, A.M.; Switzer, P.; Behar, J.V.; Hern, S.C.; Engelmann, W.H. The National Human Activity Pattern Survey (NHAPS): A resource for assessing exposure to environmental pollutants. J. Expo. Sci. Environ. Epidemiol. 2001, 11, 231252. 
[9] Lee, S.; Lam, S.; Fai, H.K. Characterization of VOCs, ozone, and PM 10 emissions from office equipment in an environmental chamber. Build. Environ. 2001, 36, 837-842.

[10] Firdhous, M.; Sudantha, B.; Karunaratne, P. IoT enabled proactive indoor air quality monitoring system for sustainable health management. In Proceedings of the 2nd IEEE International Conference on Computing and Communications Technologies (ICCCT), Chennai, India, 23-24 February 2017; pp. 216-221.

[11] Hassan, M.; Bermak, A.; Ali, A.A.S.; Amira, A. Gas identification with spike codes in wireless electronic nose: A potential application for smart green buildings. In Proceedings of the IEEE SAI Intelligent Systems Conference (IntelliSys), London, UK, 10-11 November 2015; pp. 457462.

[12] Chen, R.C.; Guo, H.Y.; Lin, M.P.; Lin, H.S. The carbon dioxide concentration detection using mobile phones combine Bluetooth and QR code. In Proceedings of the 6th IEEE International Conference on Awareness Science and Technology (iCAST), Paris, France, 29-31 October 2014.

[13] Environmental Health and Safety Office, Emory University Retrieved from https://www.ehso.emory.edu/contentforms/IAQ\%20Questionnaire.pdf. Survey title: "Indoor Air Quality Questionnaire"

[14] Gay, L.R. \& Diehl, P.L. (1992). Research Methods for Business and Management. New York: Macmillan.

[15] Occupational Safety and Health Administration. (2011). OSHA factsheet: carbonmonoxide Retrieved from website. https://www.osha.gov/OshDoc/data_General_Fact s/carbonmonoxide-factsheet.pdf 